\title{
Recent Achievements of Electron Beam Deceleration Method for FE-SEM Enhanced Elemental Analysis including Soft X-ray Emission Spectroscopy
}

\author{
S. Asahina ${ }^{1}$, Y. Sakuda ${ }^{1}$, T. Murano ${ }^{1}$, H. Takahashi ${ }^{1}$, N. Kikuchi ${ }^{1}$, K. Kawauchi ${ }^{1}$, T. Nokuo ${ }^{1}$, F. Schüth and O. \\ Terasaki
}

1. JEOL Ltd., 3-1-2 Musashino, Akishima, Tokyo, 196-8558, Japan

2. Dept of Heterogeneous Catalysis, Max-Planck-Institut für Kohlenforschung, Mülheim, Germany

3. Dept of Materials \& Environmental Chemistry, EXSELENT, Stockholm Univ, Stockholm, Sweden \& Graduate School of EEWS, KAIST, Daejeon, Republic of Korea

Recent spatial resolution and sensitivity improvements of field emission scanning electron microscopy (FE-SEM) are enormous. The analytical technique especially at low landing voltage (LV) is now heavily used in the pursuit of further understanding nano materials because of surface sensitivity. $[1,2]$ We demonstrate application of LVFE-SEM analysis coupled with large detection area EDS and a new technique called soft X-ray emission spectroscopy (SXES). The electron beam deceleration method is one way to have the necessarily small beam diameter and high probe current required of high resolution imaging even at LV. The deceleration method is here applied for high spatial resolution or chemical/bonding analysis on LVFE-SEM.

The faint X-rays emitted from the 17 nm diameter gold nanoparticles within $\mathrm{Au} @ \mathrm{TiO}_{2}$ (figure 1) are detected as energy dispersive spectroscopy (EDS) signal thanks to the large detection area of the silicon drift detector (SDD) and subsequently mapped in figures 1 (b) and (c) to register the location of gold particles seen as bright contrast in the backscattered electron micrograph in figure 1 (a). The Spatial resolution of EDS mapping is mainly determined by primary beam size and it's spreading in a sample. However, application of substrate bias in figure 1 (c) improves the resolution by thinning of primary electron beam (cf. with figure 1(b)).

We have been successful in developing SXES with energies below $0.2 \mathrm{eV}$ at Al-L that produce highly resolvable X-ray spectrum. [3,4,5,6] Therefore, the SXES is extremely valuable to understand bonding state when EDS has overlapped peek or undetectable energy range. A high electron probe current is required to detect enough soft X-ray signals from specimens. The deceleration method allows the use of a primary electron beam with higher acceleration voltage leading to higher electron probe current even at ultimately LV landing conditions. The SXES spectra taken at $4 \mathrm{keV}$ with specimen bias $-5 \mathrm{kV}$ from $\mathrm{Au} @ \mathrm{TiO}_{2}$ (figure 2 (a)) shows separated Ti (L) and $\mathrm{O}(\mathrm{K})$ spectra with ultra high-energy resolution. The comparison of $\mathrm{Ti}(\mathrm{L})$ spectra between $\mathrm{TiO}_{2}\left(\mathrm{Au} @ \mathrm{TiO}_{2}\right)$ and $\mathrm{TiN}$ (standard) on Figure 2 (b) shows different shape and energy of $\mathrm{Ti}(\mathrm{L})$ spectra that related chemical status.

\section{Reference}

[1] O.Terasaki, et al., JEOL News. 48, 21-31 (2013)

[2] M. Suga, et al., accepted to Progress in Solid State Chemistry

[3] M.Terauchi, et al., J. Electron Microscopy, 61, 1 (2012).

[4] H.Takahashi, et al., Microscopy and Microanalysis, 16 (supple. 2), 34 (2010). 
(a)

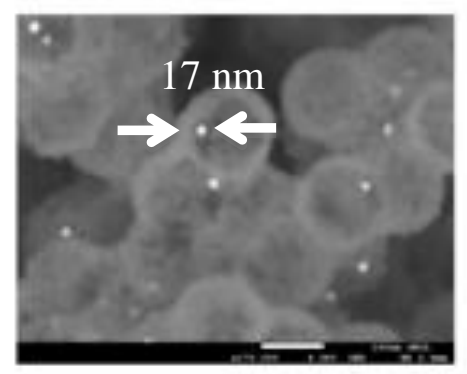

(b)

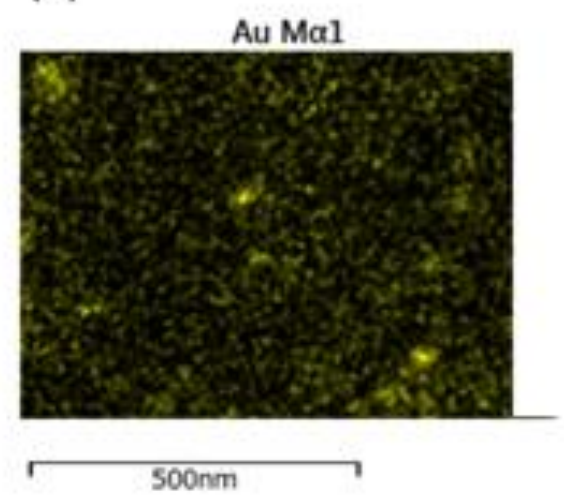

(c)

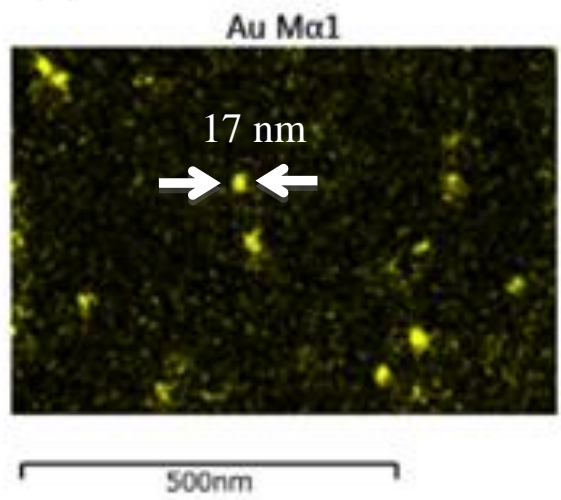

Figure.1 $\mathrm{Au} @ \mathrm{TiO}_{2}$ sample observed: (a) Backscattered image (BSE) at $4 \mathrm{kV}$; (b) and (c) Energy dispersive spectroscopic (EDS) mapping at $4 \mathrm{keV}$ with a substrate voltage of $0 \mathrm{~V}$ and $-5 \mathrm{kV}$, respectively. EDS conditions: probe current $=440 \mathrm{pA}$; SDD detection area $=150 \mathrm{~mm}^{2}$; solid angle $=$ $0.049 \mathrm{srad}$.

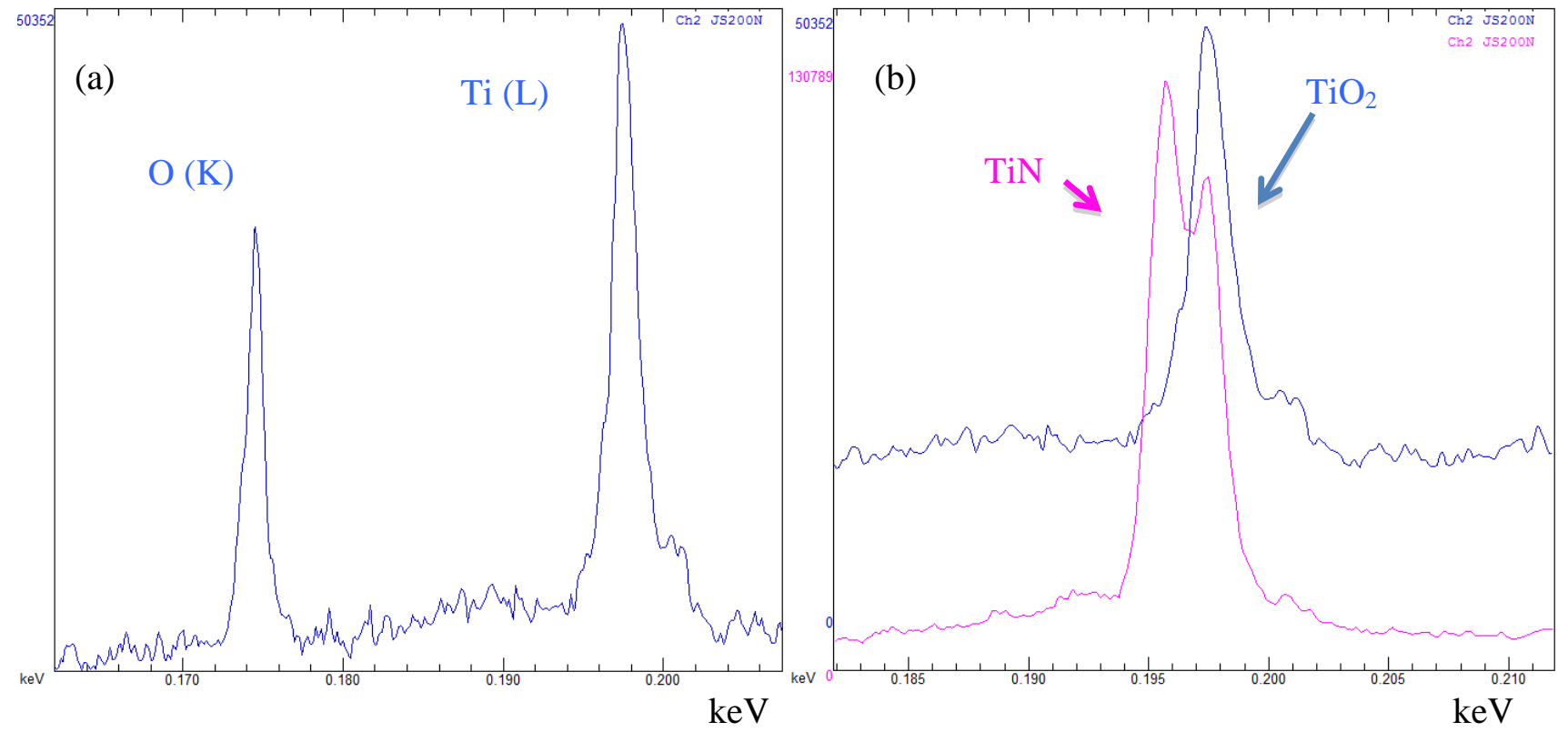

Figure.2 SXES of: (a) $\mathrm{Au} @ \mathrm{TiO}_{2}$; Conditions: primary energy $=4 \mathrm{keV}$; specimen bias $=-5 \mathrm{kV}$; probe current $=50 \mathrm{nA}$. and $(\mathrm{b})$ the $\mathrm{Ti}(\mathrm{L})$ spectra of $\mathrm{TiO}_{2}\left(\mathrm{Au} @ \mathrm{TiO}_{2}\right)$ and $\mathrm{TiN}(\mathrm{Standard})$. 